Research Paper

\title{
The associations of genetic polymorphisms in CYP1A2 and CYP3A4 with clinical outcomes of breast cancer patients in northern China
}

\author{
Xianan Bai ${ }^{1}$, Jingjing $\mathrm{Xie}^{1}$, Shanshan Sun ${ }^{1}$, Xianyu Zhang ${ }^{1}$, Yongdong Jiang ${ }^{1}$, Da \\ Pang ${ }^{1}$ \\ ${ }^{1}$ Department of Breast Surgery, Harbin Medical University Cancer Hospital, Harbin150040, China \\ Correspondence to: Da Pang, email: pangda@ems.hrbmu.edu.cn \\ Yongdong Jiang, email: jiangyongdonghmu@126.com
}

Keywords: SNP, CYP1A2, CYP3A4, breast cancer, prognosis indicator

Received: December 06, $2015 \quad$ Accepted: February 27, 2017

Published: March 18, 2017

Copyright: Xianan Bai et al. This is an open-access article distributed under the terms of the Creative Commons Attribution License 3.0 (CC BY 3.0), which permits unrestricted use, distribution, and reproduction in any medium, provided the original author and source are credited.

\section{ABSTRACT}

Background: Cytochrome P450 (CYP) 1 A2 and CYP3A4 may play a role in the differentiation of clinical outcomes among breast cancer women. This study aimed to analyze the association of genetic polymorphisms in the CYP1A2 and CYP3A4 genes with clinicopathological features, protein expression and prognosis of breast cancer in the northern Chinese population.

Results: Firstly, SNP rs11636419, rs17861162 and rs2470890 in the CYP1A2 were significantly associated with age and menstruation status. And SNP rs11636419 and rs17861162 were associated with the P53 status. Secondly, SNP rs2470890 was correlated with CYP1A2 protein expression under the co-dominant and dominant model ( $P=0.017, P=0.006$, respectively). Thirdly, for SNP rs2470890, the Kaplan-Meier 5 year survival curves showed that patients carrying genotypes CT or TT had a worse oS compared with the genotype CC carriers under both codominant and dominant model $(P<0.001, P<0.001$, respectively).

Materials and Methods: Four single nucleotide polymorphisms (SNPs) were successfully genotyped in $\mathbf{4 5 9}$ breast cancer patients using the SNaPshot method. The associations of four polymorphisms with protein expression and clinicopathological characteristics were evaluated by Pearson's chi-square test. The Cox hazard regression analysis and Kaplan-Meier survival analysis were performed to evaluate the relationship between the SNPs and overall survival (OS) of breast cancer.

Conclusions: CYP1A2 rs2470890 was significantly associated with the prognosis of patients with breast cancer and could serve as an independent impact factor of prognosis of breast carcinoma.

\section{INTRODUCTION}

Breast cancer is the most common malignancy among women worldwide [1]. The crude mortality of breast cancer doubled from year 1973-1975 to year 2004-2005 in China [2]. It is well known that breast cancer is a multifactorial disease, and that besides sex hormone, environment and lifestyle, the genetic background contributes to promote the development of breast cancer. Although a huge amount of studies reported the involvement of genetic polymorphisms in breast cancer susceptibility, studies of the genetic influence on disease progression and outcome are less frequent [3]. SNPs associated with increased severity or worsening progression of breast cancer would potentially afford a better individualized treatment of patients.

Prolonged exposure to estrogens and their oxidative metabolites is considered a crucial factor for the development and evolution of breast cancer [4]. CYP1A2 and CYP3A4, crucial enzymes belong to CYP450 superfamily, are responsible for the oxidative metabolism of estradiol and estrone in the adult human liver in addition to the metabolic deactivation of exogenous compounds, including environmental procarcinogens [5]. There are 
considerable interindividual variations in the expression and activity of CYP1A2 and CYP3A4 due to the genetic polymorphisms [6-9], which may be associated with the carcinogenic process [10]. Genetic polymorphisms of CYP1A2 have been identified as leading to interindividual variation in the susceptibility to a series of cancer, such as cholangiocarcinoma, lung, colorectal and breast cancer [11-15]. In like manner, CYP3A4 genetic variations have been also reported the functions of increasing predisposition of a wide variety of tumors [16-19]. More importantly, some variations in the CYP3A4 gene have been observed to play significantly roles in the development and outcome of several types of cancer [20-22]. However, to date, lack of studies involving the effect of single nucleotide polymorphisms (SNPs) in the CYP1A2 and CYP $3 A 4$ genes on the prognosis and survival of patients with breast cancer.

Thus, we performed a combined analysis of functional significance and Tag SNP strategies to select four potential functional SNPs in the CYP450 genes CYPIA2 and CYP3A4 from the dbSNP and HapMap databases. The minor allele frequency (MAF) of these SNPs was greater than $5 \%$, and the pair-wise $r^{2}$ was more than 0.8. As a result, 3 SNPs in CYP1A2, including rs11636419 and rs17861162 at the $3^{\prime}$-UTR and rs2470890 at exon 7, and 1 SNP, rs12333983, in CYP3A4 close to the $3^{\prime}$ site of the gene were identified. In the present study, we carried out this case-only study to evaluate the associations between these four SNPs in the CYP1A2 and CYP $3 A 4$ genes and clinicopathological characteristics, CYP1A2 and CYP3A4 protein expression and prognosis with women from Heilongjiang Province, northern China.

\section{RESULTS}

\section{Associations between genotypes of the four SNPs in $C Y P 1 A 2$ and $C Y P 3 A 4$ and clinicopathological characteristics}

The genotype distribution of all of the four SNPs selected for this study did not deviate from Hardy-Weinberg equilibrium $(P>0.05)$. We next analyzed the effects of the four SNPs in the CYP1A2 and CYP3A4 genes on a series of clinicopathological parameters in the patient cohort, including age at diagnosis and menstrual status, clinic stage, tumor size, histological grade, LNM and the status of ER, PR, HER2, Ki67 and P53. The clinicopathological features of breast cancer patients are shown in Table 1 and Supplementary Table 1.

For CYP1A2 rs11636419, under the dominant model breast cancer patients with the combined genotype $(\mathrm{GG}+\mathrm{AG})$ were more likely to have a younger age, a pre-menopause status and a P53 negative tumor relative to patients with the AA genotype $(P=0.025,0.002$ and 0.011 , respectively, Table 1). Meanwhile, significant associations were found between the CYP1A2 rs11636419 genotypes and the status of menstruation and P53 under the codominant model ( $P=0.008,0.033$, respectively, Supplementary Table 1).
For CYP1A2 rs17861162, patients with the combined genotype $(\mathrm{GG}+\mathrm{CG})$ were more likely to have a younger age, a pre-menopause status and a P53 negative tumor relative to the genotype CC carriers $(P=0.019$, 0.001 and 0.030 , respectively, Table 1$)$. However, only menopause status remained to be significantly associated with the CYP1A2 rs17861162 genotypes under the codominant model $(P=0.006$, Supplementary Table 1$)$.

The CYP1A2 rs2470890 genotypes were significantly correlated with age and menstruation status under both the dominant model and the codominant model $(P<0.001, P<0.001 ; P=0.001, P<0.001$, respectively, Table 1 and Supplementary Table 1). The carriers with the combined genotype $(\mathrm{TT}+\mathrm{TC})$ were more probably to have an older age and pre-menopausal status compared to patients with the $\mathrm{CC}$ genotype.

Unfortunately, no significant associations were found between the CYP3A4 rs12333983 genotypes and clinical features of patients with breast cancer in our samples under either the dominant model or the codominant model.

\section{$C Y P 1 A 2$ and $C Y P 3 A 4$ protein expression in breast cancer tissues}

The CYP1A2 and CYP3A4 protein expression in breast cancer tissues were shown in Figure 1 and Figure 2, respectively. Both CYP1A2 and CYP3A4 were predominantly observed staining in the cytoplasm of tumor cells. CYP1A2 and CYP3A4 protein expression was shown in 168 breast cancer tissues. Of the 168 breast cancer specimens immunostain with CYP1A2 protein specific antibody, 117 (69.6\%) were low expression, and 51 (30.4\%) were high expression. Of the 168 breast cancer specimens immunostain with CYP3A4 protein specific antibody, 131 (78.0 \%) were low expression, and 37 (22.0\%) were high expression. Under the codominant model, we found that SNP rs2470890 was significantly associated with CYP1A2 protein expression $(P=0.017$, Table 2$)$. Moreover, the patients with the combined genotypes CT + TT were more likely to have higher CYP1A2 protein expression when compared to the patients with genotypes $\mathrm{CC}$ under the dominant model $(P=0.006$, Table 2$)$. There were no significant associations between the other three SNPs and CYP1A2 or CYP $3 A 4$ protein expression either under the codominant or under the dominant model. Additionally, in the present study, there was lack of significant associations between protein expression of CYP1A2 and CYP3A4 in breast cancer tissues and OS (Table 3).

\section{Associations between genotypes of the four SNPs in CYP1A2 and CYP3A4 and OS}

In stratification analysis for different genotypes of the four SNPs in CYP1A2 and CYP3A4, the Kaplan-Meier survival curve showed a significant association between the CYP1A2 rs2470890 polymorphism and OS among the 
Table 1: Association between the genotypes and the clinicopathological variables (dominant model)

\begin{tabular}{|c|c|c|c|c|c|c|c|c|c|c|c|c|c|}
\hline \multirow{2}{*}{ Characteristics } & \multirow{2}{*}{ NO. } & \multicolumn{2}{|c|}{ rs12333983 } & \multirow{2}{*}{$\begin{array}{c}p \\
\text { value }\end{array}$} & \multicolumn{2}{|c|}{ rs11636419 } & \multirow{2}{*}{$\begin{array}{c}p \\
\text { value }\end{array}$} & \multicolumn{2}{|c|}{ rs17861162 } & \multirow{2}{*}{$\begin{array}{c}p \\
\text { value }\end{array}$} & \multicolumn{2}{|c|}{ rs2470890 } & \multirow{2}{*}{$\begin{array}{c}p \\
\text { value }\end{array}$} \\
\hline & & TT & $\mathbf{T G}+\mathbf{G G}$ & & $\mathbf{A A}$ & $\mathbf{A G}+\mathbf{G G}$ & & $\mathrm{CC}$ & $\mathbf{C G}+\mathbf{G G}$ & & $\mathrm{CC}$ & $\mathbf{C T}+\mathbf{T T}$ & \\
\hline Age (years) & 459 & & & & & & & & & & & & \\
\hline$\leq 50$ & & $139(52.5)$ & $126(47.5)$ & 0.723 & $146(55.1)$ & $119(44.9)$ & 0.025 & $149(56.2)$ & $116(43.8)$ & 0.019 & $223(84.2)$ & $42(15.8)$ & $<0.001$ \\
\hline$>50$ & & $105(54.1)$ & 89 (45.9) & & $127(65.5)$ & $67(34.5)$ & & $130(67.0)$ & $64(33.0)$ & & $135(69.6)$ & $59(30.4)$ & \\
\hline Menopause status & 459 & & & & & & & & & & & & \\
\hline Pre-menopause & & $136(52.1)$ & $125(47.9)$ & 0.604 & $139(53.3)$ & $122(46.7)$ & 0.002 & $142(54.4)$ & $119(45.6)$ & 0.001 & $224(85.8)$ & $37(14.2)$ & $<0.001$ \\
\hline Post-menopause & & $108(54.5)$ & $90(45.5)$ & & $134(67.7)$ & $64(32.3)$ & & $137(69.2)$ & $61(30.8)$ & & $134(67.7)$ & $64(32.3)$ & \\
\hline TNM stage & 403 & & & & & & & & & & & & \\
\hline I, II & & $194(52.7)$ & $174(47.3)$ & 0.859 & $221(60.1)$ & $147(39.9)$ & 0.995 & $227(61.7)$ & $141(38.3)$ & 0.845 & $289(78.5)$ & 79 (21.5) & 0.840 \\
\hline III, IV & & $19(54.3)$ & $16(45.7)$ & & $21(60.0)$ & $14(40.0)$ & & $21(60.0)$ & $14(40.0)$ & & $28(80.0)$ & $7(20.0)$ & \\
\hline Tumor stage & 396 & & & & & & & & & & & & \\
\hline $\mathrm{T} 1, \mathrm{~T} 2$ & & $195(52.7)$ & $175(47.3)$ & 0.622 & $226(61.1)$ & $144(38.9)$ & 0.264 & $232(62.7)$ & $138(37.3)$ & 0.197 & $290(78.4)$ & 80 (21.6) & 0.774 \\
\hline $\mathrm{T} 3, \mathrm{~T} 4$ & & $15(57.7)$ & $11(42.3)$ & & $13(50.0)$ & $13(50.0)$ & & $13(50.0)$ & $13(50.0)$ & & $21(80.8)$ & $5(19.2)$ & \\
\hline Histological grade & 359 & & & & & & & & & & & & \\
\hline $1-2$ & & $125(53.0)$ & $111(47.0)$ & 0.676 & $142(60.2)$ & $94(39.8)$ & 0.299 & $145(61.4)$ & 91 (38.6) & 0.406 & $178(75.4)$ & $58(24.6)$ & 0.206 \\
\hline 3 & & $68(55.3)$ & $55(44.7)$ & & $67(54.5)$ & $56(45.5)$ & & $70(56.9)$ & $53(43.1)$ & & $100(81.3)$ & $23(18.7)$ & \\
\hline LNM & 446 & & & & & & & & & & & & \\
\hline Negative & & $131(52.6)$ & $118(47.4)$ & 0.567 & $152(61.0)$ & $97(39.0)$ & 0.568 & $156(62.7)$ & $93(37.3)$ & 0.483 & $196(78.7)$ & $53(21.3)$ & 0.693 \\
\hline Positive & & $109(55.3)$ & $88(44.7)$ & & $115(58.4)$ & $82(41.6)$ & & $117(59.4)$ & $80(40.6)$ & & $152(77.2)$ & $45(22.8)$ & \\
\hline ER & 422 & & & & & & & & & & & & \\
\hline Negative & & $86(52.8)$ & $77(47.2)$ & 0.838 & $93(57.1)$ & $70(42.9)$ & 0.297 & 98 (60.1) & 65 (39.9) & 0.618 & $124(76.1)$ & 39 (23.9) & 0.301 \\
\hline Positive & & $134(51.7)$ & $125(48.3)$ & & $161(62.2)$ & $98(37.8)$ & & $162(62.5)$ & $97(37.5)$ & & $208(80.3)$ & $51(19.7)$ & \\
\hline PR & 422 & & & & & & & & & & & & \\
\hline Negative & & $105(54.1)$ & $89(45.9)$ & 0.450 & $113(58.2)$ & $81(41.8)$ & 0.452 & $119(61.3)$ & 75 (38.7) & 0.916 & $147(75.8)$ & $47(24.2)$ & 0.180 \\
\hline Positive & & $115(50.4)$ & $113(49.6)$ & & $141(61.8)$ & $87(38.2)$ & & $141(61.8)$ & 87 (38.2) & & $185(81.1)$ & 43 (18.9) & \\
\hline Her-2 & 387 & & & & & & & & & & & & \\
\hline Negative & & $186(51.7)$ & $174(48.3)$ & 0.257 & $221(61.4)$ & $139(38.6)$ & 0.549 & $224(62.2)$ & $136(37.8)$ & 0.492 & $286(79.4)$ & 74 (20.6) & 0.266 \\
\hline Positive & & $17(63.0)$ & $10(37.0)$ & & $15(55.6)$ & $12(44.4)$ & & $15(55.6)$ & $12(44.4)$ & & $19(70.4)$ & 8 (29.6) & \\
\hline Ki-67 & 418 & & & & & & & & & & & & \\
\hline Negative & & 74 (48.7) & $78(51.3)$ & 0.283 & $91(59.9)$ & $61(40.1)$ & 0.895 & $92(60.5)$ & $60(39.5)$ & 0.704 & $120(78.9)$ & $32(21.1)$ & 0.928 \\
\hline Positive & & $144(54.1)$ & $122(45.9)$ & & $161(60.5)$ & $105(39.5)$ & & $166(62.4)$ & $100(37.6)$ & & 209 (78.6) & $57(21.4)$ & \\
\hline P53 & 418 & & & & & & & & & & & & \\
\hline Negative & & $168(51.9)$ & $156(48.1)$ & 0.819 & $206(63.6)$ & $118(36.4)$ & 0.011 & $209(64.5)$ & $115(35.5)$ & 0.030 & $261(80.6)$ & $63(19.4)$ & 0.087 \\
\hline Positive & & $50(53.2)$ & $44(46.8)$ & & $46(48.9)$ & $48(51.1)$ & & 49 (52.1) & 45 (47.9) & & 68 (72.3) & $26(27.7)$ & \\
\hline
\end{tabular}

459 study breast cancer patients $(P<0.001$, Figure $3 \mathrm{~A})$. In codominant model, patients with the $\mathrm{CC}$ genotype showed significantly improved OS, whereas patients with the TT genotype showed relatively worse OS. Consistent with the above findings, in dominant model patients with the combined genotype (TT+TC) had a worse OS than patients with the $\mathrm{CC}$ genotype $(P<0.001$, Figure 3B). However, the other three SNPs were not associated with OS (data was not shown).

Multivariate analysis with hazard ratio (HR) and corresponding 95\% confidence interval (CI) was further performed by adjusting for other variables. The multivariable Cox proportional hazards model showed that in dominant model patients with the CYP1A2 rs2470890 TT+TC genotypes had significantly worse OS than those with the CC genotype $(\mathrm{HR}=1.850,95 \%$ CI 1.148-2.981, $P=0.012$, Table 3 ). Meanwhile, breast cancer patients carrying the CYP1A2 rs2470890 TT genotype had a poorer
OS compared to those with the CC genotype (HR $=3.410$, $95 \%$ CI $1.535-7.575, P=0.003$, Table 3 ). Besides, as we expected, age at diagnosis, histological grade, ER and LNM were associated with worse OS in the multivariable Cox hazard regression analysis $(P=0.007, P=0.009$, $P<0.001$ and $P<0.001$, respectively, Table 3$)$. These data support that $C Y P 1 A 2$ rs2470890 may be an independent prognostic factor of OS in breast cancer after radical mastectomy.

\section{DISCUSSION}

To the best of our knowledge, we are the first to analyse the association of the four CYP450 SNPs, including rs11636419, rs17861162, and rs2470890 in the CYP1A2 gene and rs12333983 in the CYP3A4 gene, with the clinicopathological features and prognosis of breast cancer patients. In the present study, we found that SNPs 

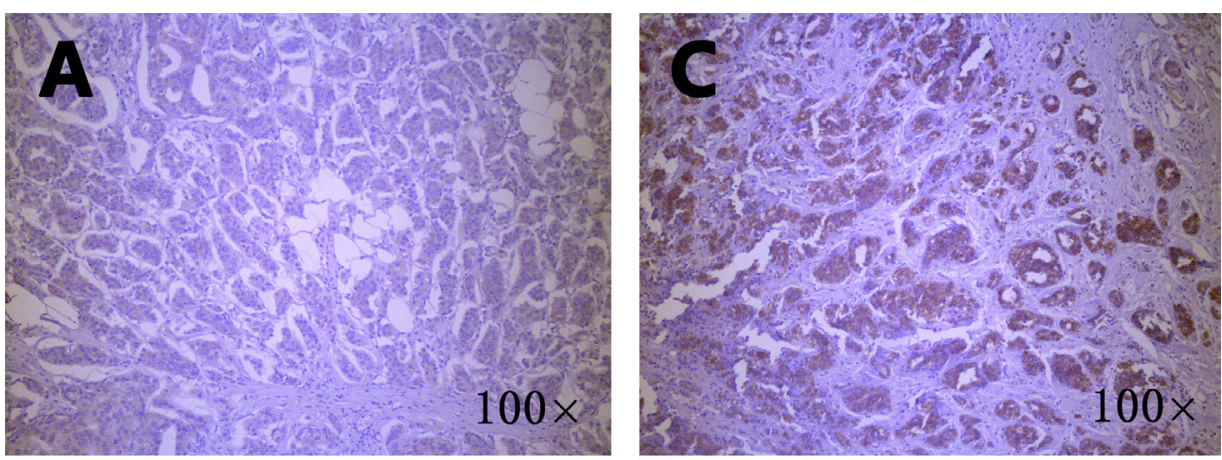

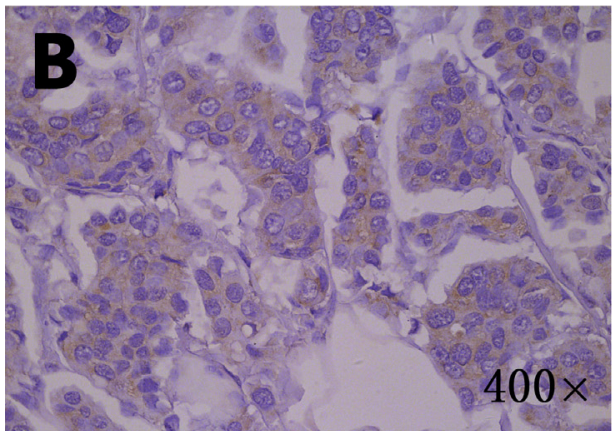

Low Expression of CYP1A2

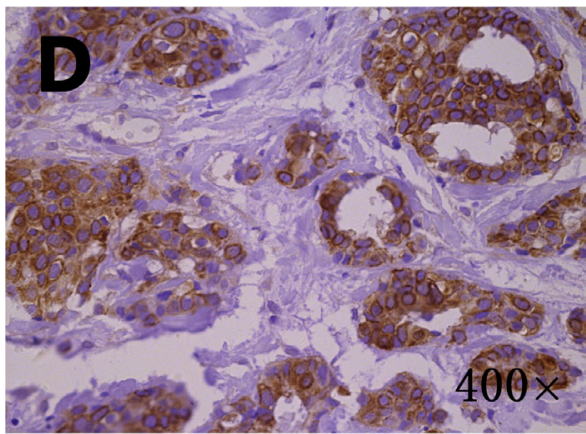

High Expression of CYP1A2

Figure 1: Immunohistochemical staining of $C Y P 1 A 2$ in breast cancer tissues. Staining for each specimen is shown at two magnification: top, 100×; bottom, 400×. CYP1A2 protein low expression specimens (A, B); CYP1A2 protein high expression specimens (C, D).
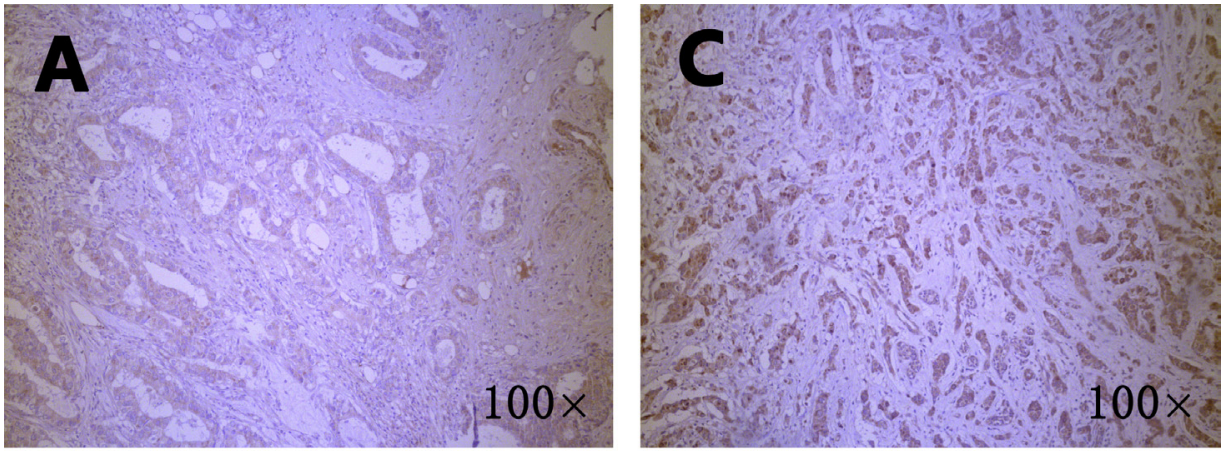

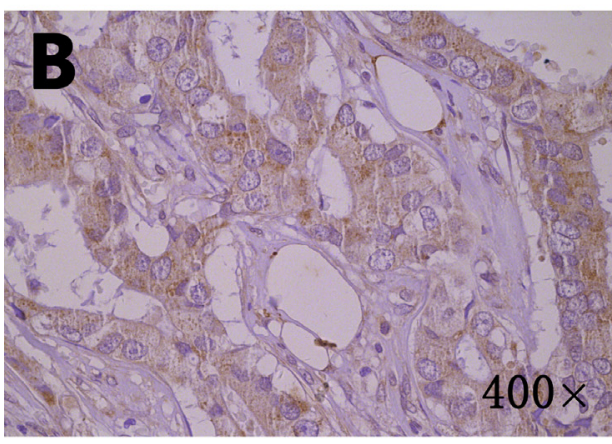

Low Expression of CYP3A4

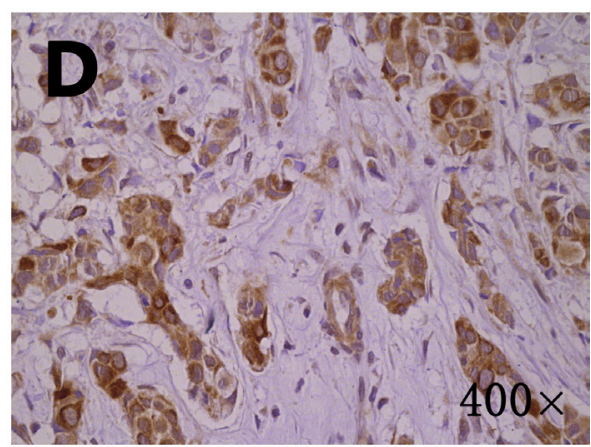

High Expression of CYP3A4

Figure 2: Immunohistochemical staining of $C Y P 3 A 4$ in breast cancer tissues. Staining for each specimen is shown at two magnification: top, 100×; bottom, 400×. CYP3A4 protein low expression specimens (A, B); CYP3A4 protein high expression specimens (C, D). 
Table 2: Association of $C Y P 1 A 2$ and $C Y P 3 A 4$ genetic polymorphisms with protein expression

\begin{tabular}{|c|c|c|c|c|c|}
\hline \multirow{2}{*}{ SNP } & \multirow{2}{*}{ Genotype } & \multirow{2}{*}{ NO. } & \multicolumn{2}{|c|}{ protein expression } & \multirow{2}{*}{$p$ value } \\
\hline & & & Low (\%) & High (\%) & \\
\hline \multirow[t]{4}{*}{ rs12333983 } & $\mathrm{TT}$ & 86 & $68(51.9 \%)$ & $18(48.6 \%)$ & \\
\hline & $\mathrm{TG}$ & 72 & $56(42.7 \%)$ & $16(43.2 \%)$ & \\
\hline & GG & 10 & $7(5.3 \%)$ & $3(8.1 \%)$ & 0.806 \\
\hline & $\mathrm{TG}+\mathrm{GG}$ vs TT & 82 & $63(48.1 \%)$ & $19(51.4 \%)$ & 0.726 \\
\hline \multirow[t]{4}{*}{ rs11636419 } & AA & 98 & $65(55.6 \%)$ & $33(64.7 \%)$ & \\
\hline & $\mathrm{AG}$ & 61 & $45(38.5 \%)$ & $16(31.4 \%)$ & \\
\hline & GG & 9 & $7(6.0 \%)$ & $2(3.9 \%)$ & 0.526 \\
\hline & $\mathrm{AG}+\mathrm{GG}$ vs $\mathrm{AA}$ & 70 & $52(44.4 \%)$ & $18(35.3 \%)$ & 0.269 \\
\hline \multirow[t]{4}{*}{ rs17861162 } & $\mathrm{CC}$ & 102 & $68(58.1 \%)$ & $34(66.7 \%)$ & \\
\hline & CG & 56 & $41(35.0 \%)$ & $15(29.4 \%)$ & \\
\hline & GG & 10 & $8(6.8 \%)$ & $2(3.9 \%)$ & 0.529 \\
\hline & $\mathrm{CG}+\mathrm{GG}$ vs $\mathrm{CC}$ & 66 & $49(41.9 \%)$ & $17(33.3 \%)$ & 0.297 \\
\hline \multirow[t]{4}{*}{ rs2470890 } & $\mathrm{CC}$ & 120 & $91(77.8 \%)$ & $29(56.9 \%)$ & \\
\hline & $\mathrm{CT}$ & 35 & $20(17.1 \%)$ & $15(29.4 \%)$ & \\
\hline & $\mathrm{TT}$ & 13 & $6(5.1 \%)$ & $7(13.7 \%)$ & 0.017 \\
\hline & $\mathrm{CT}+\mathrm{TT}$ vs $\mathrm{CC}$ & 48 & $26(22.2 \%)$ & $22(43.1 \%)$ & 0.006 \\
\hline
\end{tabular}

rs11636419, rs17861162 and rs2470890 in the CYP1A2 gene were associated with some clinical features. More importantly, CYP1A2 rs2470890 allele T was significantly correlated with unfavourable prognosis of breast cancer patients. The data suggested that CYP1A2 rs 2470890 might serve as a novel genetic indicator to evaluate breast cancer prognosis and guide clinical therapy.

CYP1A2 and CYP3A4 have key roles in the metabolic activation of pre-carcinogenes and catalyse the metabolism of endogenous substrates such as retinoic and bile acids and steroid hormones such as testosterone and oestrogen [23]. The level of estrogen associated with breast cancer risk of postmenopausal women is directly related to menstruation status and age of the patients [24]. In the present study, we found that SNPs rs11636419, rs17861162 and rs2470890 were significantly associated with age and menstruation status of breast cancer patients. Similarly, coffee consumption combined with $C Y P 1 A 2 * 1 \mathrm{~F}$ genotype was demonstrated to modify age at breast cancer diagnosis and estrogen receptor status [25]. Moreover, a meta-analysis of 46 casecontrol studies indicated that $C Y P 1 A 2 * 1 \mathrm{~F}$ polymorphism was associated with estrogen-related breast and ovarian cancer risk, but not lung, colorectal, bladder, endometrial, pancreatic and gastric cancer [13]. These indicated that CYP1A2 genetic polymorphisms might be associated with enzyme inducibility and enzymatic activity, resulting in metabolic disorders of estrogen/progesterone and thereby contributing to increased susceptibility to breast cancer [26]. The results indicated that the three SNPs in the CYP1A2 gene might alter the activity of CYP1A2 which act on estrogen metabolism and thus influence the susceptibility of different period women to breast cancer.

CYP1A2 rs 2470890 is a $\mathrm{C} / \mathrm{T}$ synonymous variation which was first identified in the Russian population [27]. Chen et al. [28] found that the allele $\mathrm{C}$ was associated with increased hepatocellular carcinoma (HCC) susceptibility in Chinese population, in HBsAg seronegative individuals, and in heavy smokers. A metaanalysis showed no evidence of significant associations between CYP1A2 rs2470890 and lung cancer risk among Caucasian and Latinos [14]. However, thus far, there has been no evidence involving the role of CYP1A2 rs2470890 played in breast cancer. In our study, we found strong correlations of CYP1A2 rs2470890 with age and menstrual status under the dominant model as well as under the codominant model. Kaplan-Meier 5 year survival curves and multivariate analysis demonstrated breast cancer patients with the CYP1A2 rs2470890 allele T suffered worse OS compared to wild type allele carriers. Besides, rs2470890 was significantly associated with the CYP $1 A 2$ protein expression not only under the codominant model but also under the dominant model. In the light of the above findings, CYP1A2 rs2470890 might have an effect on the progression of breast cancer and could serve as a novel prognostic biomarker.

SNPs rs11636419 and rs17861162 are both located at the 3 '-UTR of the CYP1A2 gene. In the previous study, our team found they were associated with the dose of epidural ropivacaine in patients undergoing breast cancer surgery [29]. In the present study, we found the two polymorphisms were significantly correlated with age 
Table 3: Prognostic factors in the cox proportional hazards model

\begin{tabular}{|c|c|c|c|c|c|c|}
\hline Factors & OR & $\begin{array}{c}\text { Univariate } \\
95 \% \mathrm{CI}\end{array}$ & $p$ value & OR & $\begin{array}{c}\text { Multivariate } \\
95 \% \text { CI }\end{array}$ & $p$ value \\
\hline \multicolumn{7}{|l|}{ Age (years) } \\
\hline$\leq 50 />50$ & 1.686 & $(1.188-2.393)$ & 0.003 & 1.903 & (1.193-3.036) & 0.007 \\
\hline \multicolumn{7}{|l|}{ TNM stage } \\
\hline I, II / III, IV & 2.979 & $(1.835-4.835)$ & $<0.001$ & & & \\
\hline \multicolumn{7}{|l|}{ Tumor stage } \\
\hline $\mathrm{T} 1, \mathrm{~T} 2$ / T3, T4 & 2.010 & $(1.104-3.662)$ & 0.022 & & & \\
\hline \multicolumn{7}{|l|}{ Histological grade } \\
\hline $1-2 / 3$ & 2.051 & $(1.393-3.019)$ & $<0.001$ & 1.856 & $(1.167-2.950)$ & 0.009 \\
\hline \multicolumn{7}{|l|}{ Lymph node status } \\
\hline Negative/Positive & 2.907 & $(1.994-4.237)$ & $<0.001$ & 3.264 & $(1.919-5.552)$ & $<0.001$ \\
\hline \multicolumn{7}{|l|}{ ER status } \\
\hline Negative/Positive & 0.469 & $(0.322-0.685)$ & $<0.001$ & 0.394 & $(0.249-0.625)$ & $<0.001$ \\
\hline \multicolumn{7}{|l|}{ PR status } \\
\hline Negative/Positive & 0.531 & $(0.362-0.778)$ & 0.001 & & & \\
\hline \multicolumn{7}{|l|}{ Her-2 status } \\
\hline Negative/Positive & 2.005 & $(1.070-3.758)$ & 0.030 & & & \\
\hline \multicolumn{7}{|l|}{ Ki-67 status } \\
\hline Negative/Positive & 1.323 & $(0.878-1.993)$ & 0.180 & & & \\
\hline \multicolumn{7}{|l|}{ P53 status } \\
\hline Negative/Positive & 1.190 & $(0.770-1.839)$ & 0.434 & & & \\
\hline \multicolumn{7}{|c|}{ CYP1A2 Pr-expression } \\
\hline Low/High & 1.016 & $(0.528-1.955)$ & 0.961 & & & \\
\hline \multicolumn{7}{|c|}{ CYP3A4 Pr-expression } \\
\hline Low/High & 0.798 & $(0.369-1.723)$ & 0.565 & & & \\
\hline \multicolumn{7}{|l|}{ rs12333983 } \\
\hline AA/GA & 0.849 & $(0.585-1.231)$ & 0.387 & & & \\
\hline $\mathrm{AA} / \mathrm{GG}$ & 1.237 & $(0.638-2.400)$ & 0.529 & & & \\
\hline $\mathrm{AA} / \mathrm{GA}+\mathrm{GG}$ & 0.899 & $(0.633-1.278)$ & 0.553 & & & \\
\hline \multicolumn{7}{|l|}{ rs11636419 } \\
\hline $\mathrm{CC} / \mathrm{CT}$ & 1.108 & $(0.770-1.595)$ & 0.580 & & & \\
\hline $\mathrm{CC} / \mathrm{TT}$ & 0.746 & $(0.302-1.847)$ & 0.527 & & & \\
\hline $\mathrm{CC} / \mathrm{CT}+\mathrm{TT}$ & 1.060 & $(0.744-1.509)$ & 0.748 & & & \\
\hline \multicolumn{7}{|l|}{ rs17861162 } \\
\hline $\mathrm{CC} / \mathrm{CG}$ & 1.016 & $(0.699-1.477)$ & 0.932 & & & \\
\hline $\mathrm{CC} / \mathrm{GG}$ & 1.022 & $(0.471-2.216)$ & 0.956 & & & \\
\hline $\mathrm{CC} / \mathrm{CG}+\mathrm{GG}$ & 1.017 & $(0.712-1.453)$ & 0.926 & & & \\
\hline \multicolumn{7}{|l|}{ rs2470890 } \\
\hline $\mathrm{CC} / \mathrm{CT}$ & 1.933 & $(1.295-2.884)$ & 0.001 & 1.557 & $(0.910-2.665)$ & 0.106 \\
\hline $\mathrm{CC} / \mathrm{TT}$ & 3.006 & $(1.558-5.799)$ & 0.001 & 3.410 & $(1.535-7.575)$ & 0.003 \\
\hline $\mathrm{CC} / \mathrm{CT}+\mathrm{TT}$ & 2.103 & $(1.457-3.035)$ & $<0.001$ & 1.850 & $(1.148-2.981)$ & 0.012 \\
\hline
\end{tabular}

OR: odds ratio; CI: confidence interval; Pr-expression: protein expression. Note: (A/B), A is the reference. 
and the status of menstruation and P53. However, we did not find the evidence concerning their influence on breast cancer survival.

In addition, SNP rs 12333983 is an A/T variation in close proximity to the CYP $3 A 4$ gene $3^{\prime}$ end. In our study, we did not find any association of CYP1A2 rs12333983 with clinicopathological characteristics or prognosis of breast cancer. To date, there are no references to the associations between CYP1A2 rs12333983 and clinicopathological characteristics and prognosis of any cancer.

In our study, we did not find any association of protein expression of $C Y P 1 A 2$ and $C Y P 3 A 4$ in breast cancer tissues with the prognosis of patients. In like manner, no significant correlation between CYP3A4 expression and clinicopathological factors as well as disease site of breast cancer was observed in other studies [30, 31]. Nevertheless, CYP1A2 protein expression in noncancerous liver tissue was identified as the predictive candidate for postoperative recurrence of HCC [32]. The different results might due to the entirely different tissues employed in the studies. In any case, the above results need to be further investigated in larger numbers of cohorts and multicenter studies.

In interpreting our results of the current study, some limitations need to be addressed. Firstly, since the population recruited only from northern China, it does not permit extrapolating the results to other ethnic groups as the allele frequency patterns vary greatly between different ethnic groups. Secondly, when we designed the experiment scheme, we did not consider the associations of CYP1A2 and CYP3A4 genetic polymorphisms with the response to treatment and chemotherapeutic drug toxicity. Thus, the participants received combination chemotherapy with excessive potential confounding factors limited further analysis. Thirdly, the size of the current study was only a relatively small number in the specific population.

In summary, the present study indicated that CYP1A2 rs2470890 was associated with breast cancer prognosis among women in northern China. The findings would promise us a functional profiling of the CYP1A2 gene and understand the biological processes associated with breast cancer formation and progression. CYP1A2 rs2470890 alone or in combination with other polymorphisms in the oestrogens metabolism related genes might serve as promising prognostic biomarkers of breast cancer. However, more in-depth studies are still needed to perform in different ethnicities in order to validate the associations between genetic polymorphisms in the CYP1A2 and CYP3A4 genes and breast cancer to reveal underlying molecular mechanism.

\section{MATERIALS AND METHODS}

\section{Study subjects}

In this study, a total of 459 breast cancer patients were recruited from the Department of Breast Surgery at Harbin Medical University Cancer Hospital from November 2008 until May 2009. The pathological specimens of patients were diagnosed with breast cancer by two pathologists. The participants were excluded from this study if they were genetically related within three generations or previously received neoadjuvant treatment. The Ethical Committee of Harbin Medical University (Harbin Medical University, 268 Xuefu Road, Nangang District, Harbin, China; the protocol number: 2006-Yan069; the date of approval: March 18, 2006) approved the present study. After providing informed consent, each
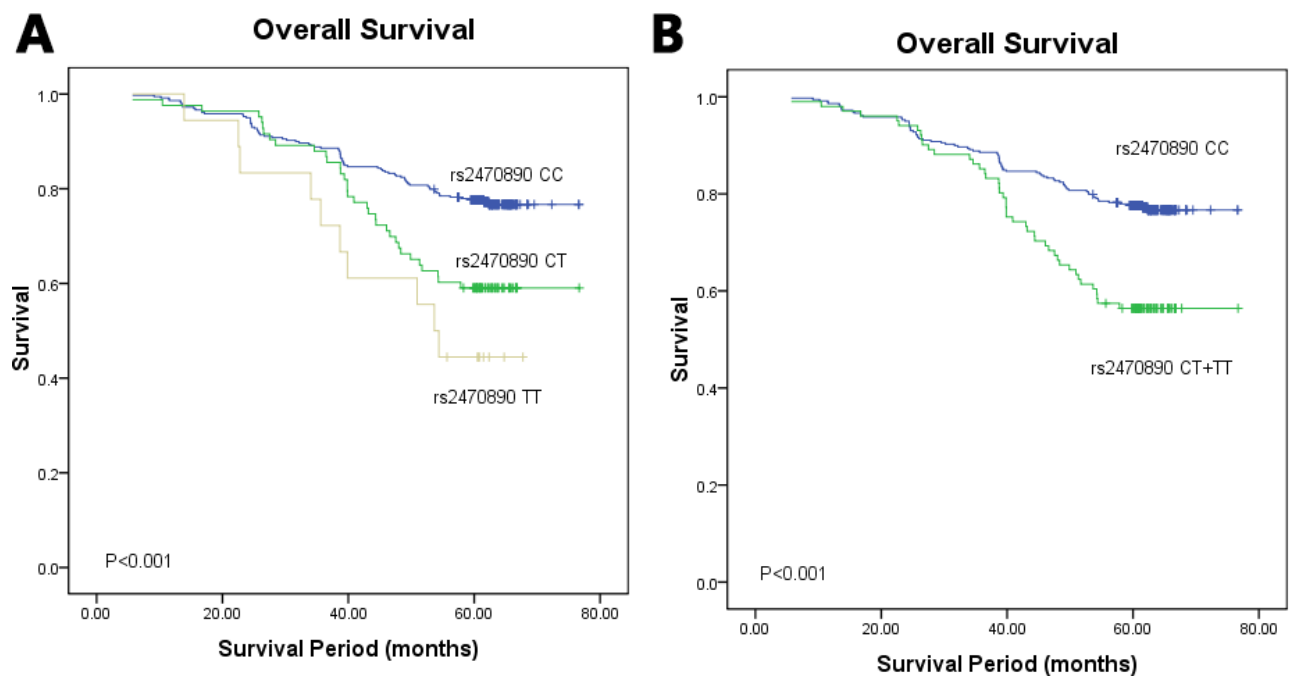

Figure 3: Kaplan-Meier survival curves of breast cancer patients carrying different genotypes of $C Y P 1 A 2$ rs2470890. (A) The codominant model; $\chi^{2}=19.150, P<0.001$. The mean survival time of CC, CT and TT genotype carriers were $66.967,95 \%$ CI $65.001-68.933 ; 61.057,95 \%$ CI 56.683-65.431; 50.445, 95\% CI 41.994-58.915, respectively; (B) the dominant model; $\chi^{2}=16.528$, $P<0.001$. The mean survival time of CC, CT + TT genotype carriers were 66.967, 95\% CI 65.001-68.933; 59.875, 95\% CI 55.812-63.937, respectively. 
participant was interviewed to collect detailed information on their demographic characteristics and provided $5 \mathrm{ml}$ of venous blood. The clinical pathological characteristics information of the 459 patients included was obtained from their medical files (Table 4). The age of the patients at diagnosis was $49.47 \pm 10.10$ years old (ranging from 27 to 91 years old).

All breast cancer patients were tested for the status of oestrogen receptor (ER), progesterone receptor (PR), human epidermal growth factor receptor 2 (HER2), P53 and $\mathrm{Ki} 67$, assayed in paraffin-embedded, formation-fixed tissue. Immunohistochemical staining for ER and PR was performed using a conventional detection method and was considered positive if $1 \%$ or more of the nuclei in the invasive component of the tumour were stained. Positive staining for Her-2 was defined based on the percentage of tumour cells and the intensity of membrane staining. No staining observed or membrane staining of fewer than $10 \%$ of the tumour cells was scored as 0 . Faint or barely perceptible incomplete membrane staining detected in more than $10 \%$ of the tumour cells was scored as $1+$. Weak to moderately complete membrane staining observed in more than $10 \%$ of the tumour cells was scored as $2+$. Strong complete membrane staining observed in more than $10 \%$ of the tumour cells was scored as $3+$. Scores of 0 to $1+$ were regarded as negative and $3+$ were regarded as positive. We selected a $\mathrm{Ki} 67$ index of $14 \%$ as the optimal cut point for human visual assessment. For P53, positive staining of more than $10 \%$ of the tumour cells was defined as positive tumour expression and staining of $10 \%$ or fewer of the cells as negative tumour expression.

\section{Follow-up}

Patients were followed regularly for 5 years at the Third Affiliated Hospital of the Harbin Medical University. Clinical records were obtained from the follow-up department of the hospital. All of the patients were followed until death or the study closing date (June 1, 2014). The OS, which measured death from any case, was the assessment used for the prognostic analyses.

\section{Genomic DNA extraction and genotyping analysis}

Genomic DNA was extracted from ethylene diamine tetraacetic acid (EDTA) anti-coagulated whole blood samples using the AxyPrep Blood Genomic DNA Miniprep Kit (Axygen Biotechnology, Tewksbury, MA, USA). The SNaPshot SNP assay was performed to detect dimorphisms of the four CYP450 SNPs. Data were analysed using the GeneMapper 4.0 Software (Applied Biosystems, Foster City, CA, USA). For quality control purposes, the genotyping was performed without knowledge of the subjects' status. Moreover, $5 \%$ of the samples were randomly selected for repeated genotyping by a different technician and the reproducibility was $100 \%$. The average call rate for all of the SNPs was higher than 99\%. The four CYP450 SNPs were rs11636419, rs17861162 and rs2470890 in the CYP1A2 gene and rs12333983 in the CYP3A4 gene.

\section{Immunohistochemical Staining of $C Y P 1 A 2$ and CYP3A4}

The formalin-fixed, paraffin-embedded samples were cut into $4 \mu \mathrm{m}$ and stained with H\&E for tumor confirmation. The tissue sections were dried at $70^{\circ} \mathrm{C}$ for $3 \mathrm{~h}$. After deparaffinization and hydration according to the standard procedures, sections were washed in phosphate-buffered saline (PBS; $3 \times 3 \mathrm{~min}$ ). After washing in distilled water, sections were washed in PBS $(3 \times 5 \mathrm{~min})$ and were then treated with $0.01 \mathrm{~mol} / \mathrm{L}$ citrate buffer $(\mathrm{pH}$ 6.0) and were exposed to heat induced epitope retrieval for $1 \mathrm{~min}$. The washed sections were treated with $3 \% \mathrm{H}_{2} \mathrm{O}_{2}$ for $20 \mathrm{~min}$ in the dark. The sections were incubated overnight at $4^{\circ} \mathrm{C}$ with primary antibody $C Y P 1 A 2$ (1:100 dilution, a recombinant rabbit monoclonal antibody, BOSTER: PB0574) and CYP3A4 (1:50 dilution, a recombinant rabbit monoclonal antibody, BOSTER: PB1111). After washing in PBS $(3 \times 5 \mathrm{~min})$, each section was incubated with the secondary antibody (an anti-rabbit antibody, ZSGB-BIO: PV6001) at $37^{\circ} \mathrm{C}$ for $30 \mathrm{~min}$. After washing in PBS $(3 \times 5 \mathrm{~min})$, each section was treated with diaminobenzadine (DAB: ZSGBBIO: ZLI-9018) working solution at room temperature for 3 min and 3 minutes and 30 seconds, respectively, and then washed in distilled water.

\section{Evaluation of $C Y P 1 A 2$ and $C Y P 3 A 4$ protein expression by immunohistochemistry}

The immunohistochemical staining of CYP1A2 and $C Y P 3 A 4$ were scored by combining the proportion and intensity of positively stained tumor cells. Staining intensity was classified into four groups: level 0 (no staining), level 1 (weak staining = light yellow), level 2 (moderate staining = yellow brown) and level 3 (strong staining $=$ brown). The percentage $(0-100 \%)$ of the extent of reactivity was scored as follows: 0 (no positive tumour cells), 1 (fewer than $10 \%$ positive tumour cells), 2 (10-50\% positive tumour cells) and 3 (more than 50\% positive tumour cells). Staining index (SI) was calculated as a proportion score $\times$ staining intensity score. The final scores $\leq 4$ were considered to be low expression, and the remainder were classified as high expression. The slides were examined by pathologists who were blinded to the clinical data.

\section{Statistical analyses}

The genotype frequencies were tested for HardyWeinberg equilibrium using the chi-square test. The 
Table 4: Summary of the clinicopathologic characteristics of the breast cancer patients

\begin{tabular}{|c|c|c|c|}
\hline Characteristics & & No. of cases & Percent (\%) \\
\hline \multirow[t]{2}{*}{ Age (years) } & $\leq 50$ & 265 & 57.7 \\
\hline & $>50$ & 194 & 42.3 \\
\hline \multirow[t]{2}{*}{ Menopause status } & Pre-menopause & 261 & 56.9 \\
\hline & Post-menopause & 198 & 43.1 \\
\hline \multirow[t]{3}{*}{ TNM stage } & I, II & 368 & 80.2 \\
\hline & III, IV & 35 & 7.6 \\
\hline & Unknown & 56 & 12.2 \\
\hline \multirow[t]{3}{*}{ Tumor stage } & $\mathrm{T} 1-\mathrm{T} 2$ & 370 & 80.6 \\
\hline & $\mathrm{T} 3-\mathrm{T} 4$ & 26 & 5.7 \\
\hline & Unknown & 63 & 13.7 \\
\hline \multirow[t]{3}{*}{ histological grade } & $1-2$ & 236 & 51.4 \\
\hline & 3 & 123 & 26.8 \\
\hline & Unknown & 100 & 21.8 \\
\hline \multirow[t]{3}{*}{ LNM } & Negative & 249 & 54.2 \\
\hline & Positive & 197 & 42.9 \\
\hline & Unknown & 13 & 2.8 \\
\hline \multirow[t]{3}{*}{ ER status } & Negative & 163 & 35.5 \\
\hline & Positive & 259 & 56.4 \\
\hline & Unknown & 37 & 8.1 \\
\hline \multirow[t]{3}{*}{ PR status } & Negative & 194 & 42.3 \\
\hline & Positive & 228 & 49.7 \\
\hline & Unknown & 37 & 8.1 \\
\hline \multirow[t]{3}{*}{ Her-2 status } & Negative & 360 & 78.4 \\
\hline & Positive & 27 & 5.9 \\
\hline & Unknown & 72 & 15.7 \\
\hline \multirow[t]{3}{*}{ Ki-67 status } & Negative & 152 & 33.1 \\
\hline & Positive & 266 & 58.0 \\
\hline & Unknown & 41 & 8.9 \\
\hline \multirow[t]{3}{*}{ P53 status } & Negative & 324 & 70.6 \\
\hline & Positive & 94 & 20.5 \\
\hline & Unknown & 41 & 8.9 \\
\hline
\end{tabular}

associations of polymorphisms in the CYP1A2 and CYP3A4 genes with the clinicopathological variables, including age, menstruation status, tumor size, histological grade, lymph node metastasis (LNM), TNM pathologic stage and the status of ER, PR, HER-2, Ki-67 and P53 were evaluated by a Pearson's chi-square test. The Cox proportional hazards model was used to estimate the independent prognostic factors for OS. Risk ratios and their 95\% confidence intervals were recorded for each marker. The Kaplan-Meier analysis was applied to compare the survival of the patients with different genotypes. The Pearson's chi-square test was used to evaluate the correlations between SNPs of the CYP1A2 and CYP3A4 genes and their protein expression. All statistical tests were two-sided, and a $p$ value equal to or less than 0.05 was considered statistically significant. Statistical analyses were performed using SPSS for Windows software (version 16.0; SPSS, Chicago, IL, USA).

\section{ACKNOWLEDGMENTS}

This study was approved by the Ethical Committee of Harbin Medical University. The authors thank all of the volunteers for providing blood samples and all of the research staff for their contributions to this project. 


\section{CONFLICTS OF INTEREST}

The authors declare that they have no conflicts of interest.

\section{FINANCIAL SUPPORT}

This study was supported by the China Postdoctoral Science Fund, (Yongdong Jiang, Grant No. 2015M571445) and the National Natural Science Foundation of China, (Yongdong Jiang, Grant No. 81202075).

\section{REFERENCES}

1. Ferlay J, Soerjomataram I, Dikshit R, Eser S, Mathers C, Rebelo M, Parkin DM, Forman D, Bray F. Cancer incidence and mortality worldwide: sources, methods and major patterns in GLOBOCAN 2012. Int J Cancer. 2015; 136:E359-386.

2. Wang L, Zhang Y, Shi JF, Dai M. [Disease burden of famale breast cancer in China]. Zhonghua Liu Xing Bing Xue Za Zhi. 2016; 37:970-976.

3. Shan J, Mahfoudh W, Dsouza SP, Hassen E, Bouaouina N, Abdelhak S, Benhadjayed A, Memmi H, Mathew RA, Aigha, II, Gabbouj S, Remadi Y, Chouchane L. Genome-Wide Association Studies (GWAS) breast cancer susceptibility loci in Arabs: susceptibility and prognostic implications in Tunisians. Breast Cancer Res Treat. 2012; 135:715-724.

4. Russo J, Hasan Lareef M, Balogh G, Guo S, Russo IH. Estrogen and its metabolites are carcinogenic agents in human breast epithelial cells. J Steroid Biochem Mol Biol. 2003; 87:1-25.

5. Yamazaki H, Shaw PM, Guengerich FP, Shimada T. Roles of cytochromes P450 1A2 and 3A4 in the oxidation of estradiol and estrone in human liver microsomes. Chem Res Toxicol. 1998; 11:659-665.

6. Chu W, Fyles A, Sellers EM, McCready DR, Murphy J, Pal T, Narod SA. Association between CYP3A4 genotype and risk of endometrial cancer following tamoxifen use. Carcinogenesis. 2007; 28:2139-2142.

7. Westlind A, Lofberg L, Tindberg N, Andersson TB, Ingelman-Sundberg $M$. Interindividual differences in hepatic expression of CYP3A4: relationship to genetic polymorphism in the 5 '-upstream regulatory region. Biochem Biophys Res Commun. 1999; 259:201-205.

8. Dobrinas M, Cornuz J, Oneda B, Kohler Serra M, Puhl M, Eap CB. Impact of smoking, smoking cessation, and genetic polymorphisms on CYP1A2 activity and inducibility. Clin Pharmacol Ther. 2011; 90:117-125.

9. Ghotbi R, Christensen M, Roh HK, Ingelman-Sundberg M, Aklillu E, Bertilsson L. Comparisons of CYP1A2 genetic polymorphisms, enzyme activity and the genotypephenotype relationship in Swedes and Koreans. Eur J Clin Pharmacol. 2007; 63:537-546.
10. Bozina N, Bradamante V, Lovric M. Genetic polymorphism of metabolic enzymes P450 (CYP) as a susceptibility factor for drug response, toxicity, and cancer risk. Arh Hig Rada Toksikol. 2009; 60:217-242.

11. Khvostova EP, Pustylnyak VO, Gulyaeva LF. Genetic polymorphism of estrogen metabolizing enzymes in Siberian women with breast cancer. Genet Test Mol Biomarkers. 2012; 16:167-173.

12. Ayari I, Fedeli U, Saguem S, Hidar S, Khlifi S, Pavanello S. Role of CYP1A2 polymorphisms in breast cancer risk in women. Mol Med Rep. 2013; 7:280-286.

13. Tian Z, Li YL, Zhao L, Zhang CL. Role of CYP1A2 1F polymorphism in cancer risk: evidence from a meta-analysis of 46 case-control studies. Gene. 2013; 524:168-174.

14. Bu ZB, Ye M, Cheng Y, Wu WZ. Four polymorphisms in the cytochrome P450 1A2 (CYP1A2) gene and lung cancer risk: a meta-analysis. Asian Pac J Cancer Prev. 2014; 15:5673-5679.

15. He XF, Wei J, Liu ZZ, Xie JJ, Wang W, Du YP, Chen Y, Si HQ, Liu Q, Wu LX, Wei W. Association between CYP1A2 and CYP1B1 polymorphisms and colorectal cancer risk: a meta-analysis. PloS one. 2014; 9:e100487.

16. Islam MS, Mostofa AG, Ahmed MU, Bin Sayeed MS, Hassan MR, Hasnat A. Association of CYP3A4, CYP3A5 polymorphisms with lung cancer risk in Bangladeshi population. Tumour Biol. 2014; 35:1671-1678.

17. Ali GT, Al-Azhary NM, Mokhtar DA. Frequency and prognostic significant of CYP3A4-A-290G polymorphism in acute myeloid leukemia. J Adv Res. 2014; 5:657-661.

18. Price DK, Chau $\mathrm{CH}$, Till C, Goodman PJ, Leach RJ, Johnson-Pais TL, Hsing AW, Hoque A, Parnes HL, Schenk JM, Tangen CM, Thompson IM, Reichardt JK, et al. Association of androgen metabolism gene polymorphisms with prostate cancer risk and androgen concentrations: Results from the Prostate Cancer Prevention Trial. Cancer. 2016; 122:2332-2340.

19. He XF, Liu ZZ, Xie JJ, Wang W, Du YP, Chen Y, Wei W. Association between the CYP3A4 and CYP3A5 polymorphisms and cancer risk: a meta-analysis and metaregression. Tumour Biol. 2014; 35:9859-9877.

20. Han JH, Lee YS, Kim HJ, Lee SY, Myung SC. Association between cytochrome CYP17A1, CYP3A4, and CYP3A43 polymorphisms and prostate cancer risk and aggressiveness in a Korean study population. Asian J Androl. 2015; 17:285-291.

21. Assis J, Pereira D, Gomes M, Marques D, Marques I, Nogueira A, Catarino R, Medeiros R. Influence of CYP3A4 genotypes in the outcome of serous ovarian cancer patients treated with first-line chemotherapy: implication of a CYP3A4 activity profile. Int J Clin Exp Med. 2013; 6:552-561.

22. Darwish MH, Farah RA, Farhat GN, Torbey PH, Ghandour FA, Bejjani-Doueihy NA, Dhaini HR. Association of CYP3A4/5 genotypes and expression with the survival of patients with neuroblastoma. Mol Med Rep. 2015; 11:1462-1468. 
23. Rendic S. Summary of information on human CYP enzymes: human P450 metabolism data. Drug Metab Rev. 2002; 34:83-448.

24. Fuhrman BJ, Schairer C, Gail MH, Boyd-Morin J, Xu X, Sue LY, Buys SS, Isaacs C, Keefer LK, Veenstra TD, Berg CD, Hoover RN, Ziegler RG. Estrogen metabolism and risk of breast cancer in postmenopausal women. J Natl Cancer Inst. 2012; 104:326-339.

25. Bageman E, Ingvar $\mathrm{C}$, Rose $\mathrm{C}$, Jernstrom H. Coffee consumption and CYP1A2*1F genotype modify age at breast cancer diagnosis and estrogen receptor status. Cancer Epidemiol Biomarkers Prev. 2008; 17:895-901.

26. Bradlow HL, Davis DL, Lin G, Sepkovic D, Tiwari R. Effects of pesticides on the ratio of 16 alpha/2-hydroxyestrone: a biologic marker of breast cancer risk. Environ Health Perspect. 1995; 103:147-150.

27. Tatishcheva Iu A, Mandel'shtam M, Golubkov VI, Lipovetskii BM, Gaitskhoki VS. [Four new mutations and polymorphic variants of the low density lipoprotein receptor in patients with familial hypercholesterolemia in Saint Petersburg]. Genetika. 2001; 37:1290-1295.

28. Chen X, Wang H, Xie W, Liang R, Wei Z, Zhi L, Zhang X, Hao B, Zhong S, Zhou G, Zhang L, Gao X, Zhu Y, et al. Association of CYP1A2 genetic polymorphisms with hepatocellular carcinoma susceptibility: a case-control study in a high-risk region of China. Pharmacogenet Genomics. 2006; 16:219-227.
29. Liu J, Xi H, Jiang Y, Feng Z, Hou L, Li W. Association of CYP450 single nucleotide polymorphisms with the efficacy of epidural ropivacaine during mastectomy. Acta Anaesthesiol Scand. 2015; 59:640-647.

30. Miyoshi Y, Taguchi T, Kim SJ, Tamaki Y, Noguchi S. Prediction of response to docetaxel by immunohistochemical analysis of CYP3A4 expression in human breast cancers. Breast Cancer. 2005; 12:11-15.

31. Sakurai K, Enomoto K, Matsuo S, Amano S, Shiono M. CYP3A4 expression to predict treatment response to docetaxel for metastasis and recurrence of primary breast cancer. Surg Today. 2011; 41:674-679.

32. Tanaka S, Mogushi K, Yasen M, Ban D, Noguchi N, Irie T, Kudo A, Nakamura N, Tanaka H, Yamamoto M, Kokudo N, Takayama T, Kawasaki S, et al. Oxidative stress pathways in noncancerous human liver tissue to predict hepatocellular carcinoma recurrence: a prospective, multicenter study. Hepatology. 2011; 54:1273-1281. 